\title{
A Contabilidade Rural como Ferramenta para a Tomada de Decisão Gerencial: um estudo com a Empresa Pecuária Sustentável da Amazônia (PECSA)
}

\author{
Júlio César da Silva da Cruz ${ }^{1}$, Carine Duarte Rosa ${ }^{2}$, Eduardo José Freire ${ }^{3}$ \\ Marlize Reffatti Zinelli ${ }^{4}$, Lauriano Antônio Barella ${ }^{5}$
}

\begin{abstract}
Resumo: O artigo elaborado tem a finalidade de explanar como se dá a aplicabilidade da contabilidade da pecuária e sua importância para os gestores na tomada de decisão. E tem como objetivo demonstrar a influência da contabilidade rural nas empresas rurais e como é utilizada na tomada de decisões. Foram coletados dados através de uma entrevista junto ao Gerente Geral da empresa Pecuária Sustentável da Amazônia (PECSA), e avaliado o funcionamento da contabilidade dentro da organização, e sua relação com a gestão de empresas voltadas para atividades rurais, parcerias e arrendamentos. Podendo-se afirmar que o uso da contabilidade da pecuária nas empresas rurais traz benefícios além de fins fiscais. Com o estudo feito percebe-se que a contabilidade dentro da empresa PECSA tem sua importância peculiar desde a elaboração de relatórios de custos de produção e formação de preço até o auxílio na tomada de decisões.
\end{abstract}

Palavras-chave: Contabilidade da pecuária. Contabilidade rural. Gestão. PECSA. Tomada de decisões

\section{Rural Accounting as a Tool for Management Decision Making: a study with the Sustainable Livestock Company of Amazonia (PECSA)}

\begin{abstract}
The elaborated article object to explain how accounting of livestock is applied and its importance for managers in decision making. And it aims to demonstrate how accounting of livestock in the rural enterprise occurs and how it is used in decision making. Data were collected through an interview with the General Manager of the Pecuária Sustentável da Amazônia (PECSA), and check the functioning of the accounting within the organization as well as the relationship that it has with the management of a company which is turned its rural activity to partnerships and leases. It can be stated that the use of livestock accounting in rural enterprises brings benefits beyond fiscal purposes. With the study made it is realized that the accounting within the company PECSA has its peculiar importance from the production of reports of costs of production and pricing until the aid in the making of decisions.
\end{abstract}

Key words: Livestock accounting. Rural accounting. Management. Decision-making

\footnotetext{
${ }^{1}$ Acadêmico do $4^{\circ}$ semestre do curso de Ciências Contábeis da Faculdade de Direito de Alta Floresta (FADAF).

E-mail: <jcmask@hotmail.com>.

${ }^{2}$ Acadêmica do $4^{\circ}$ semestre do curso de Ciências Contábeis da Faculdade de Direito de Alta Floreta (FADAF).

E-mail: <carine_duarte_cdr@hotmail.com>.

${ }^{3}$ Mestre em Educação pela Universidade Federal de Mato Grosso/Bolsista/Membro do Grupo de Estudos e Pesquisa em Gestão e Financiamento da Educação Básica - GEPGFEB da UFMT. Mestrando em Contabilidade no Programa de Pós-Graduação da Fundação Instituto Capixaba de pesquisas em Contabilidade, Economia e Finanças - FUCAPE business school. Endereço eletrônico: $<$ freireej7@hotmail.com>.

${ }^{4}$ Mestre em Ciências Ambientais e Desenvolvimento Sustentável pela Universidade Técnica de Comercialización y Desarrollo - UTCD (Universidad de Asunción-Paraguay) e Professora da Escola Técnica Estadual (ETE) e da Faculdade de Direito de Alta Floresta - FADAF. Endereço eletrônico: <lize.zinelli@ outlook.com.br>.

${ }^{5}$ Doutorando em Ambiente e Desenvolvimento pela Universidade do Vale do Taquari - UNIVATES, docente da Escola Técnica Estadual (ETE) e da Faculdade de Direito de Alta Floresta - FADAF. E-mail: <barella28@ hotmail.com>
} 


\section{Introduçao}

O presente artigo aborda como temática de estudo a aplicabilidade da contabilidade rural na perspectiva de instrumento gerencial de informações para a tomada de decisões. A pesquisa apresentará a utilização da contabilidade rural, mais especificamente a contabilidade da pecuária na empresa Pecuária Sustentável da Amazônia (PECSA) situada em Alta Floresta, cidade localizada na região norte do estado de Mato Grosso.

A pecuária vem crescendo consideravelmente no Brasil, junto, ela, as empresas rurais formadas por empreendedores que almejam ter lucro com essa atividade. Os pecuaristas se tornam importante nessa situação, e com o aumento da competitividade do ramo, se tem a necessidade de ferramentas para auxiliá-los no gerenciamento.

Segundo Graciano Silva (1982) as organizações rurais passaram por uma modernização, porém segundo ele essa modernização é conservadora pois manteve os sistemas de latifundiários no qual a terra sempre teve o papel de gerar renda e não o capita, essa modernização percebida se resume na verdade a aquisição de tecnologias voltadas somente para a produção e não para a gestão dos recursos.

As transformações ocorridas no setor possibilitaram o surgimento de propriedades modernas e equipadas nas mãos de proprietários rurais que ainda não desenvolveram sua eficiência profissional, esse modelo de crescimento ocorreu pelas facilidades de crédito rural que nos últimos anos tem sofrido limitações impostas pela legislação ambiental pois propriedades com passivos ambientais não desfrutam desses benefícios. O produtor se viu pressionado a tonar seus investimentos mais lucrativos e sustentáveis abrindo assim as porteiras de sua propriedade para empresas com a proposta da PECSA que se propõe a gerenciar essa propriedade rural de forma autossustentável.

A contabilidade rural entra como uma ferramenta responsável por esse gerenciamento, colaborando para que a empresa minimize seus riscos, através da administração das informações contábeis, como escrituração, contabilização e demonstração financeira auxilia na tomada de decisões sendo fundamental para o gerenciamento eficiente das atividades desenvolvidas na área rural.

A PECSA é uma organização caracterizada pela gestão e parceria agropecuária. Criada em junho de 2015, por um grupo de cinco gestores, com objetivo central de transformar a 
pecuária local em um negócio sustentável, produtivo e rentável, fortalecendo a economia regional.

A organização usa o sistema de Boas Práticas Agropecuárias para Bovinos de Corte BPA, da Embrapa, que abrangem todos os aspectos da gestão da propriedade de forma integrada. As BPAs referem-se a um conjunto de normas e de procedimentos a serem utilizados pelos produtores rurais, que além de tornar os sistemas de produção rentáveis e competitivos, asseguram também a implantação de um modelo de produção sustentável que leva em consideração o desenvolvimento econômico, ambiental e social da atividade.

Afirma Reis (2010, p. 9) "que o processo de administração de uma empresa rural é implantado mediante algumas etapas que são planejamento, organização, direção e controle". O estudo demonstra que esse modelo administrativo é seguido, pois as fazes de execução na parceria se resume em diagnosticar como a propriedade está estruturada, observando a situação dos bens operacionais da fazenda, a partir de então investir em mecanização, reforma de pastagem, infraestrutura, adequação do ambiente, entre outros, para melhor desenvolver as atividades.

É importante mencionar que, segundo o site do Canal Rural, no Mato Grosso o ramo comercial da pecuária abrange $40 \%$ da economia, evidenciando a importância da referida atividade para a economia estadual (RYNGELBLUM, 2016). O que também serve de parâmetro para verificar a importância do seu gerenciamento. Nessa linha, é fundamental os gestores compreenderem a importância e também aplicarem a contabilidade para o desenvolvimento dos negócios da pecuária. Contudo, se vê poucos estudos na academia enfocando o assunto, e/ou discutindo no campo da pecuária o uso da contabilidade na gestão rural. Assim, a abrangência do tema se justifica na medida em que são poucas publicações existentes nessa área, se vê então a oportunidade de realização de pesquisa que pudesse contribuir para reflexões acerca da aplicabilidade da contabilidade na função de auxiliar na gestão da pecuária.

A Pesquisa teve a pretensão de ser utilizada, como apoio para consulta à classe contábil, desde estudantes a profissionais da contabilidade e empresários do ramo da pecuária que possam fazer uso desse conteúdo, que tem por base responder como se dá a aplicabilidade da contabilidade na perspectiva rural, e quão é sua importância quando utilizada na tomada de decisões. Assim o objetivo geral consistiu em demonstrar como ocorre o desenvolvimento e 
os efeitos da contabilidade da pecuária na empresa PECSA, descrevendo a importância da contabilidade rural para a gestão organizacional, como ferramenta de apoio para tomada de decisão, explanando como se desenvolve a contabilidade da pecuária dentro da empresa durante o ciclo operacional e, explicitando as possíveis tomadas de decisões que ocorrem a partir dos benefícios gerados pela aplicação da contabilidade da pecuária, tomadas de decisões essas que também se fazem tanto em empresas maiores quanto menores, pois no mercado atual, o que se vê são que cada vez mais necessita-se de planejamento nas empresas.

O presente artigo encontra-se organizado além desta Introdução, em seções como embasamento teórico, resultados e discussão, considerações finais, e finalizando apresentação de lista contendo Referenciais de livros, artigos e sites consultados para o desenvolvimento do presente artigo.

\section{Embasamento Teórico}

A contabilidade da pecuária vem da contabilidade rural, essa surge da grande área contabilidade geral. Seguindo esse raciocínio, o objeto de estudo deste trabalho refere-se à contabilidade da pecuária, envolvendo, especificamente a empresa PECSA de Alta Floresta, Mato Grosso.

A contabilidade rural é essencial, uma vez que "é um dos principais sistemas de controle e informação das empresas rurais" (CREPALDI, 2011, p. 81). As empresas rurais têm com a contabilidade o controle de suas despesas, e através de informações a respeito de patrimônio e demonstrações de resultados, que ajudam nas tomadas de decisões com referência em documentos que apresentam a operação da empresa em cada período. As informações de Demonstração de Resultado de Exercício (DRE), por exemplo, traz a quem está administrando o quanto ocorreu de despesa em cada setor e se pode aumentar ou diminuir essas despesas a fim de melhorar a atividade operacional da organização. Seguindo esse raciocínio de tomada de decisão, tendo como referência relatórios contábeis, Marion (2002, p. 149) explica: "como se sabe, o objetivo básico da contabilidade por meio de relatórios pode prover os usuários de informação útil para a tomada de decisões”. Dessa forma, ambos os 
autores concordam que a contabilidade fornece relatórios que auxiliam a administração em suas decisões.

A atividade da pecuária no Brasil é maior da área rural, segundo Marion (2002, p. 25) "[...] o Brasil ostenta um dos maiores rebanhos bovinos do mundo e sua pecuária representa uma atividade econômica de grande relevância". Assim, a pecuária é um mercado de muito valor e sua organização é fundamental para ter proveito do seu potencial. E a contabilidade da pecuária vai ao encontro na medida em que proporciona relatórios necessários para as empresas rurais produzirem e terem controle de seus bens.

O que se vê, por conta da falta do uso da contabilidade rural em empresas rurais é a má organização em suas contas a pagar, a receber, seus bens etc... E com essa ausência, o produtor rural não tem controle de seu estoque. Marion (2002, p. 106) explica que, "basicamente, no Brasil, em termos de contabilidade da pecuária, há dois tipos de avaliação do estoque vivo: valores de custo e valores de mercado". Como dito, são relatórios como esse que trazem aos administradores uma boa referência na hora de tomar decisões. As empresas comportam sua atividade operacional se baseando em relatórios que realmente demonstram, O que a empresa tem? O que gasta? O que pode comprar? Entre outros

As informações repassadas pelo setor contábil em sua maioria são de extrema importância, uma vez que o gestor trata esse departamento como, aquele que sabe de tal forma como está a vida financeira e econômica da empresa.

Trazendo a contabilidade para a área do planejamento, Crepaldi $(2011$, p. 78$)$ diz que, "um sistema contábil eficiente, aliado ao bom-senso do administrador, deve proporcionar um diagnóstico realista, com a localização dos pontos fracos e fortes de cada atividade produtiva”. O que possibilitaria aos administradores ter informações para vários intentos em uma negociação, venda, compra ou outras situações do tipo, uma vez que tem em mãos o potencial da sua empresa naquele momento, e o que deve ser melhorado.

Embora a contabilidade tenha sua utilidade e relevância como instrumento para fins fiscais, atualmente são poucas as tomadas de decisões se baseando somente na utilização da mesma, e o objetivo do presente artigo, reside em explicitar as contribuições obtidas pela prática administrativa eficiente e eficaz junto ao negócio. E demonstrar também que a Contabilidade Rural, enquanto ferramenta gerencial pode, por meio da informação contábil, auxiliar no bom desenvolvimento de planos para tomada de decisões, além disso, o controle 
dos custos e a comparação dos resultados, com isso, a necessidade de investir em mecanismos disponibilizados pela Contabilidade para obtenção de informações e consequentemente, a gestão estratégica, para a otimização do potencial de cada empresa para maximizar seus lucros.

\section{Metodologia}

Metodologias são vários processos para estudar problemas e conhecer a realidade dos mesmos. Os métodos têm a finalidade de mostrar a forma que será alcançado os objetivos, como serão organizados o trabalho para se chegar a um fim (OLIVEIRA, 1997). Esses métodos permitem que os dados coletados sejam estudados e utilizar as informações deles adquiridas no artigo.

\section{Método de Abordagem}

O método de abordagem utilizado no estudo foi o indutivo, explicado pelas autoras Lakatos e Marconi (2010, p. 68) como sendo "um processo mental por intermédio do qual, partindo de dados particulares, suficientemente constatados, infere-se uma verdade geral ou universal, não contida nas partes examinadas". Informações coletadas da empresa PECSA poderão ser generalizadas a outras empresas, que se equiparem a ela, para que possam fazer uso da contabilidade rural voltada área da pecuária, como auxilio na administração. O método indutivo permite obter conclusões a partir do estudo da empresa PECSA como um dado particular.

\section{Procedimentos}

Para o método de procedimento foi utilizado o método monográfico, que tem como princípio um estudo de caso, essa pesquisa estuda a influência da contabilidade rural na 
tomada de decisões, usando informações coletadas de pessoas dos cargos administrativos e da contabilidade da organização PECSA.

A pesquisa representativa pode ser generalizada, pois fatores que relacionam a contabilidade rural, que gera informações sobre o patrimônio da empresa PECSA, com o gestor que tem sua obrigação de decidir as negociações da empresa, se repetem em outras organizações da pecuária do mesmo porte. Ou seja, o uso pelo gestor das informações geradas a partir da contabilidade rural da pecuária, como insumos, investimentos, despesas administrativas, entre outros, que estão contidas em relatórios como Demonstração do Resultado do Exercício (DRE) e Balanço Patrimonial, venha servir de auxílio para aumentar o lucro, reduzir despesas, evitar perdas, etc...

\section{Tipo de pesquisa}

No estudo fez-se uso da pesquisa exploratória, que permite nos familiarizarmos com o problema de forma explícita. Essa pesquisa envolve o levantamento bibliográfico e entrevista com pessoas entendidas do assunto pesquisado (GIL,2008). Segundo Oliveira (1997, p. 135)

\footnotetext{
Os estudos exploratórios podem ter outros aspectos, tais como o de possibilitar ao pesquisador fazer um levantamento provisório do fenômeno que deseja estudar de forma mais detalhada e estruturada posteriormente, além da obtenção de informações acerca de um determinado produto.
}

Permite aos autores do estudo um levantamento para descobrir fatos que tem relação válida com a aplicação da contabilidade na pecuária. A forma exploratória proporciona um vínculo palpável sobre o assunto na medida em que o tema escolhido não tem muitos problemas explorados, complicando a elaboração das hipóteses (BOTELHO, 2013). A pesquisa se volta para a demonstração da contabilidade na pecuária, estudando a empresa PECSA em seus departamentos, coletando dados de seus gestores para uma possível generalização. 


\section{Quanto ao problema}

$\mathrm{Na}$ abordagem da problemática foi aplicada a pesquisa qualitativa, uma vez que, conforme Botelho (2013, p. 55), "uma das principais características da abordagem qualitativa é a imersão do pesquisador no ambiente da pesquisa, isto é, o pesquisador precisa manter um contato direto e longo com o objeto da pesquisa". A pesquisa qualitativa possibilitou a identificação do problema abordado, também compreender o processo da contabilidade da pecuária desenvolvido pela empresa PECSA para, a partir de então ter noções da aplicabilidade desta ciência social no campo da tomada de decisões.

\section{Técnica de coleta de dados}

A técnica de coleta de dados utilizada foi entrevista de forma padronizada que segundo Lakatos e Marconi (2010, p.180), "é aquela em que o Entrevistador segue um roteiro previamente estabelecido; as perguntas feitas ao indivíduo são pré-determinadas. Ela se realiza de acordo com um formulário elaborado e é efetuada de preferência com pessoas selecionadas de acordo com um plano". Por meio da opinião do próprio gestor com o objetivo de conseguir informações e/ou conhecimento acerca de tal problema, para o qual se procura uma resposta. Propiciou uma situação de contato, ao mesmo tempo formal e informal, de forma a "provocar" um discurso livre, mas que atendeu aos objetivos da pesquisa e que foi significativo ao contexto investigado e academicamente relevante. Depois de realizada a mesma foi transcrita e dando continuidade foi realizada a conferência de fidedignidade, ou seja, ouviu-se a gravação tendo o texto transcrito em mãos, conferindo cada frase mudanças de entonação, interrupções etc. Para evitar respostas induzidas e reavaliar os rumos da investigação.

Todos esses métodos serviram de guia, traçando um caminho que foi seguido dentro do artigo. Assim foram utilizados esses métodos para a elaboração do artigo para auxiliar nas pesquisas bibliográficas, formulação das hipóteses, na coleta de dados, no estudo dos dados coletados, e para então a chegada a um resultado no fim do artigo elaborado. 


\section{Resultados e Discussão}

Foi realizada a entrevista com Gerente Geral da empresa PECSA, visto que é responsável pelas tomadas de decisões junto a outros integrantes da organização. Á princípio o entrevistado afirma que, a contabilidade é uma ferramenta essencial em seu trabalho, e seu uso é em maior parte a contabilidade do que em departamento financeiro essa afirmação condiz com Callado (2011, p. 86) que afirma que:

a contabilidade é desenvolvida com finalidades específicas, que podem estar relacionadas com o fornecimento de dados de custos para a medição dos lucros, determinação da rentabilidade e avaliação do patrimônio, e ainda identificar métodos e procedimentos para o controle das operações.

O gerente justifica ainda a importância de se usar a contabilidade falando que as propriedades rurais de pequeno porte dificilmente mantêm uma contabilidade em dia, sendo a PECSA uma empresa no regime tributário do lucro real, necessita assim que os lançamentos sejam feitos de forma correta. Pelo nível em que a empresa se envolve com seus clientes, tem que buscar ver o quanto eles se desenvolvem, então a contabilidade se torna o controle mais viável para mostrar como a empresa está. Isso vai ao encontro com o que Marion $(2010$, p. 2) fala, que "a necessidade de criação de meios e instrumentos para a efetivação de tais controles é hoje uma realidade latente e insofismável". Ou seja, as propriedades rurais tendem a utilizar cada vez mais formas de controles, como por exemplo, a contabilidade da pecuária, sendo utilizada não somente para fins do fisco, mas também para gestão na pecuária.

Os empresários rurais, ao lidarem com o ecossistema e, portanto, com recursos naturais lidam com uma infinidade de variáveis que necessitam ser gerenciadas então decisões estratégicas e operacionais são tomadas para se atingir objetivos predefinidos. Porém, qualquer decisão para ser efetiva deve considerar fatos e dados existentes mensuráveis e não apenas o conhecimento do empresário (REIS,2010). Estes dados são obtidos por meio dos demonstrativos utilizados pela PECSA, o entrevistado afirma: "Hoje a gente tem como principal apuração de resultado o DRE”. O Demonstrativo de Resultado do Exercício (DRE) como o próprio nome já diz, demonstra o resultado de uma empresa em determinado período, para saber se teve lucro ou prejuízo durante sua operação. Nesse sentido apuram o resultado, e 
a partir de então analisam para saber em qual situação a empresa tem mais lucro ou prejuízo, e verificam a possibilidade de mudanças. O Entrevistado ainda expõe que, quando se elaboram o DRE, sabe-se exatamente qual está sendo o resultado da PECSA, e complementa falando "esse é um desafio da pecuária porque a gente trabalha com ganho de peso de animais", e segundo o Sr. Vando é complexa a mensuração dos custos de animais em ganho de pesos. Para Marion (2010, p. 58)

\begin{abstract}
Conhecer o custo real de cada cabeça, de cada lote ou do rebanho a qualquer momento é uma informação imprescindível à gerência, não só para apurar a rentabilidade após a venda, mas também, o que é mais importante ainda, para determinar o ponto ótimo de venda, ou seja, não manter o gado quando os custos passam a ser maiores que o ganho de peso.
\end{abstract}

Nesse caso a contabilidade para PECSA servirá tanto para apuração do custo de produção, quanto para apuração do resultado, e decidir se manter a atividade com os tais custos em seu estoque é vantajoso a empresa. Custo estes que ajudam a formular o preço de venda dos serviços prestados. A respeito do estoque o entrevistado diz que trabalham com estoque de terceiros, e todos devem estar registrados no Instituto de Defesa Agropecuária (INDEA), e contabilizados exatamente como está na prática, e mesmo sendo contabilizados com rigorosidade ainda tem que fazer a contagem a cada período, para ter a real certeza de quanto é o estoque de cada filial, e no fim o estoque total.

As afirmações do Entrevistado vão ao encontro com o que diz os estudiosos da contabilidade rural, onde são poucos os sistemas de mensurações e controles para a área rural, sendo assim a contabilidade se torna a principal ferramenta de controle e de informações das empresas rurais (CREPALDI, 2011). Mesmo a utilização sendo feita mais por empresas de grande porte, pela não obrigatoriedade da utilização da contabilidade na pequena empresa rural. Assim a contabilidade tem extrema importância na área da pecuária, no que diz respeito á tomada de decisões, uma vez que pela entrevista nota-se que a empresa utiliza o resultado da aplicação da contabilidade para analisar as possíveis tomadas decisões.

A empresa PECSA trabalha com arrendamentos e parcerias, segundo Sr. Vando a empresa faz o investimento e o proprietário entra com os animais e formam uma parceria. E mais, Sr. Vando fala que "os benefícios da parceria rural é que ela tem tributação menor comparado a um arrendamento, quando o produtor arrenda uma área obrigatoriamente esse 
arrendamento tem um desconto de $27.5 \%$ de imposto de renda". Então a empresa analisa através da contabilidade da pecuária, qual opção é a mais vantajosa perante a legislação, que nesse caso o melhor seria a parceria que incide menos imposto, aumentando assim a lucratividade da empresa. Como se nota, uma analise a partir de seus contadores na legislação para identificar maneiras de se ter melhores resultados, são feitas na PECSA, mostrando que a empresa se mantém atenta a legislação, que sofre constantes mudanças no Brasil.

A competitividade tem por base a produtividade e, portanto, podemos afirmar que a base para a produtividade é a competitividade e a qualidade. A lucratividade é consequência direta dos fatores anteriormente citado (REIS 2010). A visão estratégica da empresa estudada se fundamenta no princípio de uma assistência técnica de qualidade orientada tanto por conhecimentos relacionados as práticas de produção quanto as técnicas de administração tendo a contabilidade como uma das ferramentas de trabalho.

Durante a entrevista, quando perguntado a respeito das informações que a contabilidade da pecuária proporciona a PECSA, foi mencionado a palavra "saúde", a partir disso percebe-se a visão de um administrador, que identifica que existe vida na empresa e que diariamente precisa de manutenção. Como dito faz-se uso do DRE para analisar o resultado da empresa, porém nesse momento o Entrevistado relata que também faz uso do fluxo de caixa, e junta esses dois relatórios, apurados mensalmente, para verificar como está o desempenho da empresa, daí uso da palavra "saúde". Todos esses relatórios são feitos em cada filial, seja de parceria ou arrendamento, juntando a situação de todas as filiais o Entrevistado diz que tem o desempenho da empresa como um todo, e fala o seguinte "a partir disso podemos tomar decisões sobre quais ações podemos tomar para melhorar o desempenho de cada uma". Assim a contabilidade mostra para os gestores toda a situação financeira e econômica da organização, ou seja, a "saúde" da empresa.

Trazendo a contabilidade para a perspectiva da administração verifica-se que o uso da contabilidade da pecuária de forma eficiente, com sistemas eficientes, direcionados por um administrador de bom-senso, ocasiona uma análise minuciosa e realística das fraquezas e como erradicá-las, para que a organização mantenha forte sua atividade de produção (CREPALDI, 2011). Ainda falando sobre o assunto, Crepaldi (2011, p. 210) diz que as informações de relatórios, como Plano de Contas, Balanço Patrimonial, DRE, entre outros, "é de fundamental importância para possibilitar estudos comparativos, análises e quaisquer 
outros detalhamentos extraídos da contabilidade". Isso identifica que realmente acontece na PECSA, à utilização das demonstrações contábeis e seus lançamentos para uma análise da situação econômica e financeira.

$\mathrm{Na}$ entrevista foi perguntado sobre as possíveis tomadas de decisões, chama atenção na resposta no momento que fala sobre a formação do preço de venda, que só é possível porque traçam metas a partir de seus relatórios contábeis, e através da apuração do custo de produção proporcionado pela contabilidade da pecuária da PECSA. Segundo o Entrevistado "quando a contabilidade fecha os relatórios de custo de produção, preço de compra e preço de venda, nos dá uma noção exata para onde devemos ir então", assim a formulação de preços através dos custos de produção elaborados pela contabilidade e a apuração mensal dos resultados obtidos fazem parte da rotina da empresa. O que se vê é a utilização importantíssima no momento de decidir o preço, pois é a partir dessa medida que se pode calcular a lucratividade da empresa no final de cada período. Desta forma uma tomada de decisão visa o lucro e a economia, fazendo-se uma análise sobre os demonstrativos para se decidir de maneira satisfatória, de modo que alcance os objetivos da PECSA.

O Entrevistado expressa as seguintes palavras "nossa informação a chave é contabilidade, dela tomamos as decisões, e o Contador fica bem antenado as questões tributárias, quais as incidências de tributos, impostos, quem tem toda a movimentação desde a compra de gado. Assim se a empresa tem o preço de compra elevado perante o mercado sua lucratividade diminui. Porém, conseguindo um preço baixo na compra seus serviços serão mais lucrativos, da mesma forma, se o Contador não souber que em determinado período a alíquota do Imposto sobre Circulação de Mercadorias e Serviços (ICMS) para as empresas rurais diminuiu, poderá estar pagando imposto a mais para o Estado, tendo assim prejuízos. Claramente uma empresa com Contador bem informado que busca atualização frequente, se sobre sai sobre as outras, e sua atividade de produção tende a ser mais duradora, e mais valorizada, pois fato importante a ser dito é que o mercado é exigente, quer qualidade pelo menor preço. Assim o Contador da empresa PECSA tem informação em suas mãos que junto aos administradores possam tomar decisões.

Ao citar as práticas tributárias, verifica-se a necessidade de estar atento na legislação, uma vez que esta tem mudanças frequentes, um dia se pode dormir com uma Lei dissertando uma coisa, no dia posterior a mesma pode estar modificada, e no descuido de estar desatento, 
pode ocasionar prejuízo econômico e financeiro à empresa, ou perdendo a oportunidade de aumentar a lucratividade da organização.

Com relação ao planejamento tributário, por meio da contabilidade decidiu-se que trabalhariam com o regime do Lucro Real, que segundo Vando, permite aproveitar melhor os investimentos a longo prazo e cita "por avaliarmos que o investimento inicial era mais alto, teríamos um tempo para diluir esse investimento nas propriedades produtoras, então se você não tem o planejamento, se você não tem uma contabilidade, você fica sem informação". Desta forma as informações reunidas pela contabilidade da pecuária, nos termos tributários, permitem a escolha de um regime que melhor atenda a empresa PECSA no momento, e que satisfaça por um longo prazo.

E ainda relata que "na tendência que estamos indo a fazenda, a propriedade rural vai deixar de ser uma simples propriedade e vai passar a ser uma empresa rural, onde deve ter toda a contabilidade, todos seus controles como qualquer empresa". Essa visão mostra que as propriedades rurais cada vez mais precisam se adequar as normas legislativas, e não é diferente quando se fala de contabilidade, pois o Estado tem a contabilidade com uma ferramenta a ser utilizada para verificar como está trabalhando cada empresa. No meio urbano o Estado tem seus sistemas para saber o que se passa em cada empresa. Por exemplo, os sistemas de emissão de Nota Fiscal que leva saber qual o estoque, fluxo de caixa, em outras palavras saber como funciona a operação das empresas. No meio rural ainda é difícil essas informações chegarem com o governo. Cabe a contabilidade da pecuária, mostrar ao fisco como esta determinada empresa, por meio de seus lançamentos, fazendo seus balanços e demonstrações.

Fato importante que deve se explicitar a pequena propriedade rural é não ficar utilizando a contabilidade da pecuária somente em confecção de registros contábeis, mas sim fazer uso como a PECSA, para ter tomada de decisões, e analisar o que deve ser melhorado a partir de uma visão contábil. Nas PECSA verifica-se que faz uso da contabilidade da pecuária, e que são feitos como qualquer outra empresa que não mexa com atividade rural. Assim, observaram-se aspectos de uma empresa de serviço presentes na contabilidade da PECSA, modificando alguns termos para adequação com o tipo de atividade explorada, como por exemplo, o Plano de Contas, Balanço Patrimonial, DRE, Fluxo de Caixa, entre outros. 
Concluindo este capítulo pode-se perceber a importância da contabilidade para gerenciamento a partir das demonstrações, e também para apuração dos custos da produção da empresa PECSA. Compreendeu-se então que a contabilidade é utilizada para além de fins fiscais que o governo obriga como também as demonstrações e lançamentos e está ligada a tomada decisão que o administrador pode ter no futuro. Ou seja, para gerenciamento da empresa PECSA é imprescindível a utilização da mão de obra qualificada no setor contábil, e não somente empresas de grande porte façam utilização, mas também as empresas pequenas, que estão começando ou que já atua há tempos mercado.

\section{Considerções Finais}

O presente estudo junto a empresa Pecuária Sustentável da Amazônia (PECSA) teve a finalidade de coletar informações e discuti-las para verificar o funcionamento da contabilidade dentro de sua operação, não somente a parte de lançamento contábil, mas também a utilização dela como ferramenta para gerenciar a organização.

Identificou-se que a contabilidade da pecuária tem muito a expandir no que diz a aplicabilidade em empresas de pequeno porte, e que a PECSA é uma responsável por mostra a esses pequenos produtores rurais que compensa a utilização da contabilidade para se fazer um planejamento em sua propriedade, visando lucro e economia.

Foi possível constatar que a empresa PECSA faz uso da contabilidade em seus lançamentos diários, e elaboração de relatórios, como DRE e Balanço Patrimonial, e que a aplicação da contabilidade da pecuária dentro de sua operação vai além desses registros, sendo utilizada no gerenciamento e tomada de decisões. Assim a contabilidade serve não somente para fins fiscais e preenchimento de registros, mas também para planejamento, essencial com as mudanças que frequentemente ocorrem no Brasil.

A hipótese era que se a empresa utiliza da contabilidade como fornecedora de informação ela tem uma melhor tomada de decisões, baseando-se no controle e informação que ela traz. Assim o estudo foi de encontro com a hipótese, uma vez que a pesquisa demonstrou que empresa utiliza a contabilidade para gerar informação e ter uma melhor 
tomada de decisões, baseando-se no controle e informação que ela traz para gerenciar a empresa.

O contador deve estar atento e verificar no que a empresa pode melhorar em suas compras, vendas, investimentos entre outros, de acordo com a legislação contribuindo assim para melhor organização e em sua tomada de decisões. Nesse sentido Crepaldi (2011, p.40) diz que no ramo da pecuária "é de suma importância a necessidade de profissionais e de mão de obra qualificados, para operarem nas atividades rurais, tanto na produção como na área administrativa, visando buscar um controle econômico-financeiro mais rigoroso". Como já foi dito, atualização constante dos profissionais da empresa pode gerar lucro e economia, demonstrando que na empresa PECSA, segundo Sr. Vando, a atualização de seu pessoal se torna importante para bom aproveitamento na produtividade da organização.

O presente artigo teve suas dificuldades na execução primeiramente com o prazo de execução e finalização do mesmo, considerado curto, porém foi possível aproveitar os dados pertinentes, as informações necessárias para a elaboração do artigo, e esses dados foram de encontro com o material do embasamento teórico, como os próprios autores falam, tem carência em informações a respeito da contabilidade da pecuária, visto que são poucos os autores que visam tratar o assunto.

\section{Referências}

BOTELHO, Joacy Machado; CRUZ, Vilma Aparecida Gimenes da. Metodologia científica. 1. ed. São Paulo: Pearson Education do Brasil, 2013.

CREPALDI, Silvio Aparecido. Contabilidade rural: uma abordagem decisorial. 6. ed. São Paulo: Atlas,2011.

GIL, Antônio Carlos. Métodos e técnicas de pesquisa social. 6. ed. São Paulo: Atlas, 2008.

LAKATOS, Eva Maria; MARCONI, Marina de Andrade. Fundamentos de metodologia científica. 7. ed. São Paulo: Atlas, 2010.

MARION, José Carlos. Contabilidade rural: contabilidade agrícola; contabilidade da pecuaria; imposto de renda - pessoa jurídica.7. ed. São Paulo: Atlas, 2002. 
OLIVEIRA, Silvio Luiz de. Tratado de metodologia cientifica. 1. ed. São Paulo: Pioneira,1997.

REIS, Luis Felipe Sousa Dias. Agronegócios: qualidade na gestão. 1.ed. Rio de Janeiro: Qualitymark, 2010. 400p.

RYNGELBLUM, Ivan. Pecuária domina 40\% do território de Mato Grosso. Canal rural, São Paulo, 2016. Disponivel em: $<$ http://www.canalrural.com.br/noticias/boi-gordo/pecuariadomina-territorio-mato-grosso-57503>. Acesso em: 18 set. 2016.

Como citar este artigo (Formato ABNT):

CRUZ, Júlio C.da S da; ROSA, Carine D.; FREIRE, Eduardo J.; ZINELLI, Marlize R.; BARELLA, Lauriano A. A Contabilidade Rural como Ferramenta para a Tomada de Decisão Gerencial: um estudo com a Empresa Pecuária Sustentável da Amazônia (PECSA). Id on Line Revista Multidisciplinar e de Psicologia, 2017, vol.11, n.37, p. 392-407. ISSN: 1981-1179.

Recebido: 30.08.2017

Aceito: 01.09 .2017 